\title{
FROM LANGUAGE LABORATORY TO LANGUAGE LEARNING ROOM
}

\section{Hector Hammerly, Simon Fraser University}

Until 1960, the School of Languages of the Foreign Services Institute (U.S. Department of State, Arlington, Virginia) provided its students with the opportunity to study language tapes with individual two-track tape recorders, the type of facilities that came to be known as "library" laboratories. As an instructor there from 1958 to 1961, I was able to observe repeatedly the beneficial effect of such tape study undertaken by individual F.S.I. students in addition to their class hours.

The installation of a monitored laboratory with console in $\mathbf{1 9 6 0}$ was therefore a source of puzzlement to me. Taking students away from an hour of instruction in small groups to a room where each of them could make many mistakes without being heard or corrected by the instructor/monitor seemed quite a disadvantage. There were several other pedagogical disadvantages. The only apparent advantage was that, while monitoring at the console, the instructor could save energy and use his vocal cords less than in class.

Since then, I have had numerous occasions to observe the pedagogical weaknesses of laboratory monitoring, ${ }^{1}$ its greatest weakness being probably the fact that the average student is on his own over 95\% of the time, so that monitoring is more illusory than real. Since students are on their own for almost all the time they spend in a monitored laboratory anyway, they should be taught to monitor themselves. Fortunately, it seems that, despite numerous assertions to the contrary, this may be possible. ${ }^{2}$

As is well known, professional enthusiasm and federal grants combined to make language laboratories a booming enterprise during the early sixties. These facilities were, with few exceptions, of the "traditional," highly regimented, lockstep practice type rather than of the "library," individual study type.

As is also well known, a general disillusionment with traditional language laboratories set in during the late sixties. Although there is no doubt that many factors contributed to this situation, two important negative factors seem to have been excessive laboratory regimentation (students simply dislike being treated like parading soldiers) and the disappointing software available (publishers' tapes that merely dupli- 


\section{Learning Room}

cate their printed materials). The late sixties also saw the start of the individualized instruction movement, resulting in an increasing emphasis on the abilities, needs and goals of individual students and in an increased amount of individual study as opposed to lockstep, mass instruction.

The general disillusionment with traditional language laboratories together with the individualization movement combined to produce, at least in some of the institutions where the spoken language continued to be an important goal, a new type of facility, which for lack of a better term could be called a "language learning room." Unlike a traditional laboratory, a language learning room, while it may be used at times for small or even large group activities, contains equipment which is used primarily for individual study. In this aspect, then, the profession has gone full circle, from individual study equipment (no equipment in most public schools) during the fifties to large group study hardware during the sixties and again to individual study equipment during the seventies, with most of the responsibility for learning being placed directly on the student.

The language learning room differs from the earlier library-type laboratories, however, in several important respects. Its equipment may go far beyond individual tape recorders in carrels (with or without a console $)^{3}$ and may include audiovisual machines of various types as well as such facilities as conversation tables, a reference area, filing cabinets, magazine racks, realia, etc. Moreover, the room may be designed strictly for individualized language programs or for a combination of individualized and lockstep programs. Numerous plans for such rooms have appeared in the professional literature; the reader is therefore referred to it. 14

The language learning room planned for the French Language Training Center proposed for Simon Fraser University (S.F.U.) may be particularly interesting, for (a) it represents the fourth stage see below - in the development of language learning facilities at S.F.U. and (b) it is planned so as to accommodate a variety of pedagogical philosophies and programs - lockstep audiovisual, lockstep audiolingual, individualized audiovisual, individualized audiolingual, and possibly other approaches, both tried and experimental.

The four stages in the development of language learning facilities at S.F.U. have been (1) traditional monitored laboratories, since the opening of the University in 1965; (2) the addition of two small library-type laboratories, 1967; (3) gradual renovation of all laboratories and change to standard cassette equipment, with each laboratory allowing both monitored group work and individual study, 1974-197?; and (4) the language learning room for the planned French Language Training Center. The diagram and discussion below should give the reader a clear idea of the proposed facilities. 


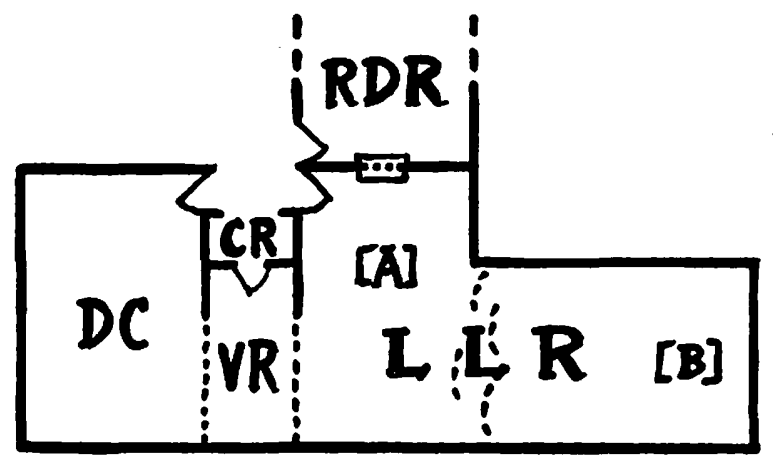

The diagram depicts the language learning areas only. Other areas of the proposed Center include a workshop, a lounge/conference room, and a $20^{\prime} \times 30^{\prime}$ resource and documentation room, only part of the latter being shown in the diagram above. "DC" designates the demonstration classroom, 20' $\times 30^{\prime}$ in size and with built-in equipment for various types of presentations-the demonstration classroom would serve primarily the needs of lockstep programs. Between the demonstration classroom and the language learning room ("LLR") there will be access to a viewing room ("VR") through a coatroom ("CR"). The $10^{\prime} \times 20^{\prime}$ viewing room will accommodate up to fourteen observers (teachers, student teachers, and other visitors) on swivel chairs on a raised platform, with one-way glass views of the demonstration classroom and the language learning room.

The language learning room will be L-shaped and have a total area of 1,200 square feet, subdivided into two $20^{\prime} \times 30^{\prime}$ areas, (A) and (B). Area $B$ will be a console-equipped laboratory allowing both individual and group, monitored and unmonitored study of tapes as well as oral tests; it will have 25 booths with quality cassette recorders, booths which, in order to avoid student distraction, will be not only acoustically but also visually isolated. (This isolation will be achieved not only by avoiding face-to-face visual contacts but also by extending the booth dividers one foot into the aisles.) The movement of students between area B and area A, and viceversa, will be easy, since instead of doors there will be staggered six-foot sound screens between the two areas. 
Area $\mathrm{A}$ will be used for small group activities as well as individual study with equipment other than built-in cassette recorders. A tablehigh counter will go all around the walls of area $\mathrm{A}$ and will have some fixed audiovisual equipment and outlets for a variety of portable machines (both portable hardware and all software will be borrowed through a window counter connecting area $A$ with the resource and documentation room ("RDR"). Towards the center of area A there will be tables for conversation in small groups, a reference center, zling cabinets for the keeping of individualized learning packets and student progress records, and so forth.

It should by now be clear that the students in individualized programs offered by the Center would use primarily the language learning room, moving freely between areas A and B. During the early part of their programs, however, and occasionally thereafter, they would have the possibility of having large group activities, since the demonstration classroom and the lounge/conference room would also be easily accessible.

Another aspect that should be mentioned is the increasing use at S.F.U. of portable cassette machines for loan to students. It has been found that equipment loan is about the only way in which students who have to be absent due to illness or other causes can manage to keep up with their language programs. Loan equipment is also a solution to the needs of evening students, who seldom can avail themselves of laboratory facilities during the normal hours, even if the normal hours include some evening hours. Unfortunately an adequate solution has not yet been found for the problem of equipment loss or damage -among the possibilities considered have been insurance, deposits, and equipment use fees. Despite this problem, the pedagogical value of loan equipment is such that the proposed French Language Training Center would no doubt have some, for the use of both lockstep and individualized program students. (Of course, the equipment has to be of sufficient fidelity to meet the requirements of second language study; this rules out inexpensive cassette machines, at least for the learning of new language material.)

The change at S.F.U. from traditional language laboratories to flexible language learning rooms has been slow and is yet to be completed. Along the way there have been many difficulties-financial, technical, and other. The author only hopes that eventually language learning facilities at S.F.U. will make it easier, more efficient, more convenient, and more pleasant for students to learn a second language. This is, after all, what progress in this field is all about. 
NOTES

'See Hector Hammerly, "The Myth of Language Laboratory Monitoring," The Modern Language Journal, Vol. LVIII, No. 7 (November 1974), pp. 336-339 for a detailed discussion of this topic.

2Without adequate visual aids to pronunciation it may indeed be impossible. Very preliminary results of an experiment using step 3 of the Articulatory Pictorial Transcription (A.P.T.) for Spanish, however, indicate that with such an aid language learners may be able to develop rather quickly self-monitoring abilities. (The A.P.T.'s use symbols that remind students of the actual articulation of second language sounds; A.P.T.'s for Spanish, French, German, and English as a Second Language are presented in Hector Hammerly, The Articulatory Pictorial Transcriptions: New Aids to Second Language Pronunciation, available from Second Language Publications, P.O. Box 1700, Blaine, Wash.)

${ }^{3} \mathrm{~A}$ console, even if it does not offer many pedagogical advantages, can be quite useful for (a) the copying of tapes and (b) the administration of mass speaking tests. The latter does not even require a remote control function.

4For room arrangements accommodating both types of programs see, for example, the following:

Arvel B. Clark, "Planning for Individualized Instruction: An Administrator's Perspective," in Howard B. Altman and Robert L. Politzer, eds., Individualizing Foreign Language Instruction (Rowley, Mass.: Newbury House, 1971), p. 56.

David M. Braswell, "Individualizing a Junior High School Foreign Language Program," in Howard B. Altman, ed., Individualizing the Foreign Language Classroom (Rowley, Mass.: Newbury House, 1972), p. 104.

For room arrangements accommodating individualized instruction in particular see, for example, the following:

Francois Hugot et al., Report of the Working Committee on Innovative Trends in Foreign-Language Teaching, in James W. Dodge, ed., Leadership for Continuing Development (1971 Northeast Conference Reports), p. 100.

Hector Hammerly, "Report on the 1972 Meeting of ACTFL," in Walter C. Kraft, ed., Proceedings of the 1973 Pacific Northwest Conference on Foreign Languages (Corvallis, Ore.: Dept. of Modern Languages, Oregon State University, 1973), pp. 69-70.

Gerald E. Logan, Individualized Foreign Language Learning: An Organic Process (Rowley, Mass.: Newbury House, 1973), p. 106. 


\section{TANDBERG LEARNING SYSTEMS}

While you read this page, we are installing a Tandberg Learning System somewhere in the world. In fact, two systems per working day, each one tailored to the professional's requirements.

On 5 continents, in 55 countries.

$1 / 4$ million students per day learn something through a Tandberg Learning System.

\section{Why?}

- Quality

- Reliability

- Durability

- Serviceability

In short: Tandberg Systems do the Job ... Professionally, for professionals... And have for 15 years.

See us at booth number 847 at the AECT Show.

\section{Tandberg of America, Inc.}

Labriola Court, Armonk, New York.10504

$\square$

Please send more information on Tandberg Educational Products.

Name

Title Phone

(area code)

Institution

Address

City State Zip 


\section{Sony's MOBILAB... the first mobile language lab.}

With Sony's MOBILAB, languages can be taught in any room, under a tree, even sur la plage. And MOBILAB can go from school to school for maximum utilization with minimum equipment cost.

It's about the same reasonable price as a wireless installation, but without that poor wireless sound that has teachers everywhere crying "oncle!"

On the other hand, fixed labs do have good sound, true. But the cost? cott im hommel!

MOBILAB gives you the quality sound of a fixed lab but at a much lower cost.

But no other system, fixed or wireless, offers as much operating ease ancoteaching flexibility: all three teaching levels plus independent study (the students can take the player/recorders with them).

Each of the compact MOBILAB cabinets includes console, teacher player/recorder, 10 student player/recorders, and headsets for all. Two or more MOBILAB units can be quickly, easily coupled to instruct any number of students.

" "Un sistema maravilloso de lengua!" can now be very clearly enunciated, anywhere, with the portable MOBILAB.

Write to Sony Corporation of America, Information Center, Dept. 249-E, Box 1594, Trenton, N. J. 08607.

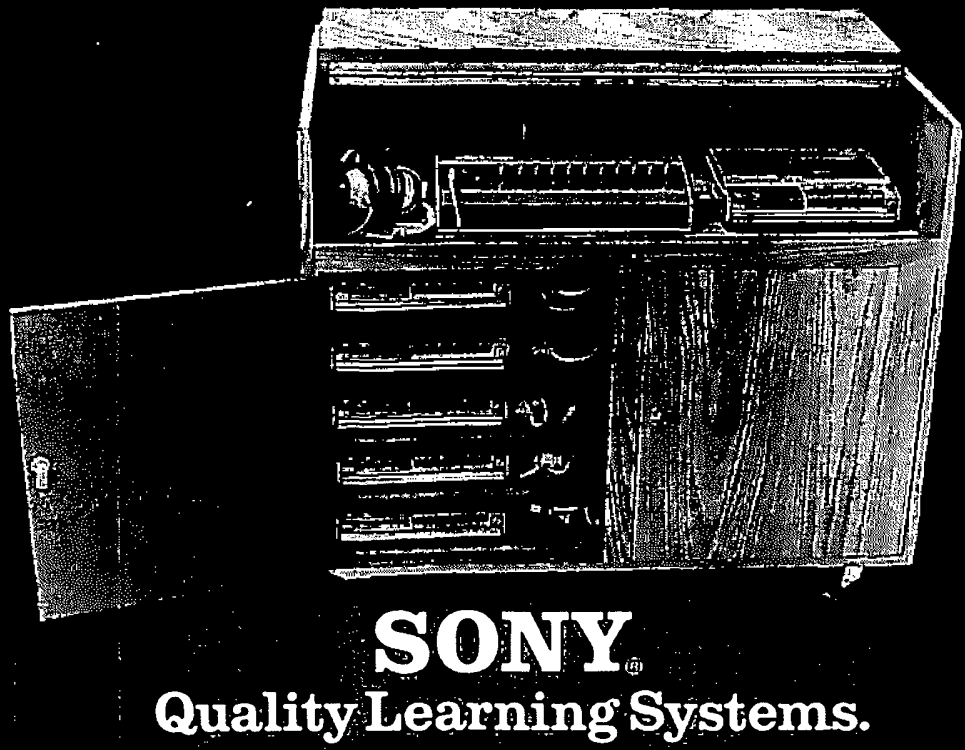




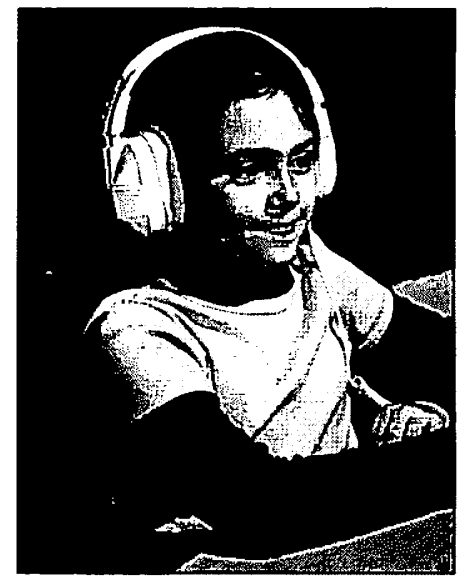

AVEDEXTERITY means BETTER QUALITY AUDIO SYSTEMS for... FOREIGN LANGUAGE DEPARTMENT

Level II and Level III Labs. Meets all requirements BUSINESS EDUCATION DEPARTMENT Shorthand/Typing Skill-Building Lab. FM Wireless or Wired MUSIC DEPARTMENT Music Appreciation-Mono/Stereo Quality Listening with Headsets

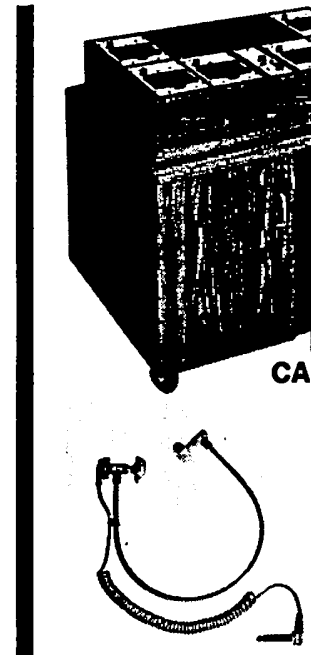

\section{LIBRARIES}

Listening Center System for all Tapes and Records
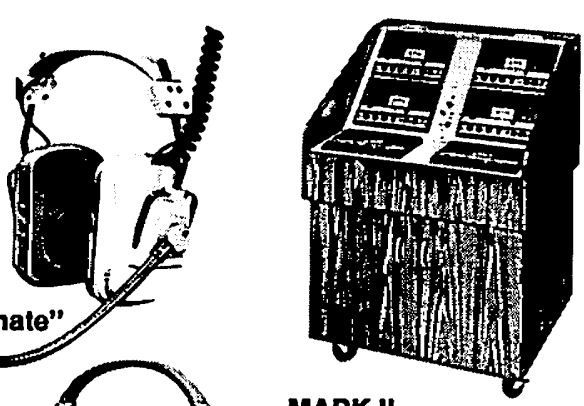

"Underthe-Chin"
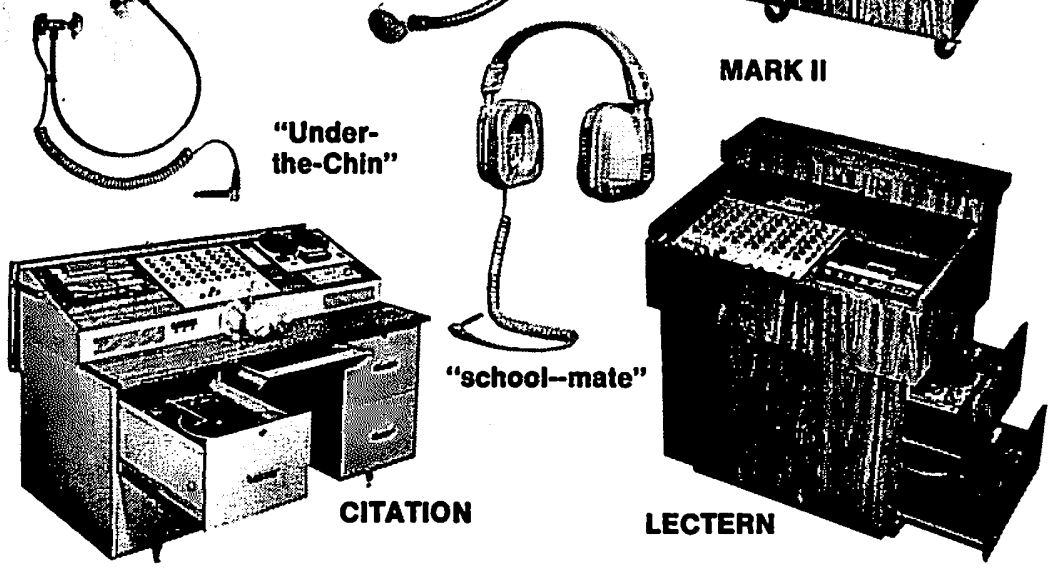

Avedex offers a wide range of skill-building Audio Systems. Let us help you plan a system to fit your requirement. Call us (312) 679-8210 or write for more information. 


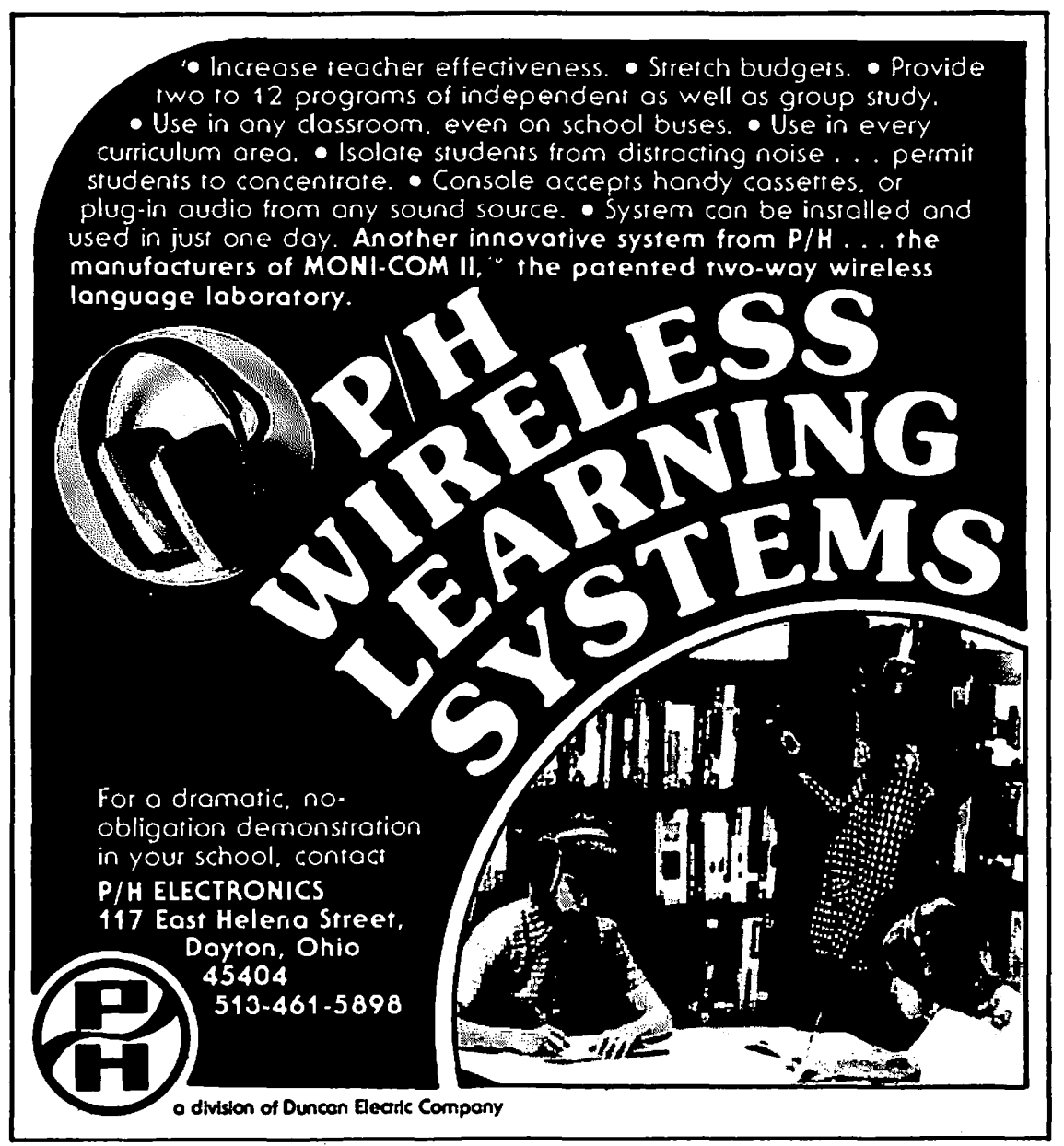

